\title{
Imagen, medios y telecolonialidad: hacia una crítica decolonial de los estudios visuales
}

\author{
Image, Mediums and Telecoloniality: towards a \\ Decolonial Criticism of Visual studies
}

\author{
Christian León \\ Universidad de Buenos Aires, Argentina \\ c1leon@yahoo.com
}

Resumen - El presente artículo propone pensar los procesos de visualidad desde América Latina a partir del denominado «giro decolonial». Intenta entender la relación estructural que existe entre prácticas visuales y estructuras de poder mundial surgidas en el contexto del sistema-mundo moderno. Plantea la relación existente entre las tecnologías, discursos, prácticas y sujetos asociados a las imágenes y la analítica de la colonialidad del poder, el conocimiento y el ser. Analiza las jerarquías de distinto tipo producidas a través de dispositivos visuales en el contexto de la división internacional del trabajo tecnológico, la racialización global de la población y la economía mundializada de las imágenes.

Palabras clave: Visualidad, Cine, Arte, Colonialidad, Geopolítica

Abstract - This paper discusses the visuality processes in Latin America since the called «decolonial turn» approach. It analyzes the structural relationship between visual practices and global power arising in the context of the modern world system. It seeks to study the relationship between visual technologies, discourses and practices and the analytics of the coloniality of power, knowledge and being. It addresses the different types of hierarchies produced through a visual dispositive in the context of the international division of technology labor, the racialization of the population, and the global economy of images.

Keywords: Visuality, Cinema, Arts, Coloniality, Geopolitics 
Los estudios visuales que están en desarrollo en América Latina tienen como desafío pendiente la construcción de un lugar de enunciación donde sus saberes se sitúen histórica y geopolíticamente. En este sentido, tanto la crítica a la tradición occidental de las historias y teorías del arte, como el audiovisual, ambos provenientes del primer mundo, es una tarea imprescindible. La particularidad de los procesos de visualidad en nuestro subcontinente plantea singularidades históricas, culturales y epistémicas que no han logrado ser abordadas en toda su complejidad. En esta búsqueda, el denominado «giro decolonial» permite articular una serie de entradas conceptuales para comprender «la heterogeneidad histórico estructural» de la visualidad en América Latina ${ }^{1}$ y asumir las tareas pendientes que dejaron los movimientos antiimperialistas del arte y el cine latinoamericano a lo largo del siglo $\mathrm{xx}^{2}$.

En los últimos años, la crítica cultural (Richard, 82) y los estudios culturales (García Canclini, 38) han puesto en discusión la importancia de considerar las imágenes en un campo ampliado de producción, circulación y consumo, inserto en relaciones geopolíticas en donde la asimetría cultural a nivel internacional es norma. Sin embargo, estos esfuerzos parecen estar destinados al fracaso ya que no encuentran la manera de establecer las relaciones constitutivas entre visualidad y geopolítica en el contexto de la modernidad occidental. La crítica decolonial, por su parte, se origina en el debate sobre las matrices de poder generadas por la colonización en los campos del saber, la cultura, las representaciones y su reestructuración constante, a lo largo de las distintas oleadas de modernización y occidentalización por las que ha atravesado América Latina. A partir de este abordaje, se hace posible entender la relación estructural que existe entre prácticas significativas (sean estas discursivas, visuales o corporales) y estructuras de poder mundial surgidas con lo que el sociólogo estadounidense Immanuel Wallerstein ha denominado "sistema-mundo moderno»". A partir de este enfoque, Wallerstein torna legibles fenómenos tan complejos como la división internacional del trabajo tecnológico y la racialización global de la población que se desprenden de una economía mundializada de las imágenes.

\section{AMÉRICA LATINA Y LA MODERNIDAD VISUAL}

El pensamiento decolonial genera crítica en el análisis de los dispositivos, las instituciones y las prácticas relacionadas con la producción de discurso y visualidad dentro de las geopolíticas coproducidas por los centros y las periferias del sistema-mundo

\footnotetext{
Para un balance de los planteamientos de la crítica decolonial ver Castro-Gómez y Grosfoguel (2007). Para una definición del concepto de «heterogeneidad histórico-estructural» ver Quijano (2000).

2 A lo largo de siglo xx, en distintas regiones de América Latina surgieron vanguardias y movimientos estéticos que tomaron la bandera de la crítica al imperialismo cultural y el eurocentrismo. Estos esfuerzos críticos, sin embargo, estuvieron acosados por una contradicción performativa: pretendían impugnar el sistema cultural moderno desde el mismo lenguaje, valores y epistemologías occidentales. Muchos de estos movimientos, como la antropofagia brasileña o el tercer cine argentino, plantearon hacer del arte un caballo de batalla contra el imperialismo norteamericano pero al mismo tiempo afirmaron la supremacía de la cultura letrada occidental, la figura viril y patriarcal del autor y adhirieron a un concepto homogéneo de cultura nacional.

3 Para una introducción al método de análisis del sistema-mundo moderno ver Wallerstein (2004).
} 
moderno ${ }^{4}$. Desde esta perspectiva, la modernidad surge signada por la colonialidad, dicho de otro modo, «la colonialidad es constitutiva de la modernidad» (Mignolo, «Colonialidad del poder y subalternidad», 158). En palabras de Enrique Dussel:

En Occidente, «la modernidad» que se inicia con la invasión de América por parte de los españoles [...] es la apertura geopolítica de Europa al Atlántico; es el despliegue y control del «sistema-mundo» en sentido estricto y la invención del sistema colonial que durante trescientos años irá inclinando lentamente la balanza económica y política a favor de la antigua Europa aislada y periférica. Todo lo cual es simultáneo al origen y desarrollo del capitalismo. Es decir: modernidad, colonialismo, sistema mundo y capitalismo son aspectos de una misma realidad simultánea y mutuamente constituyente. (Dussel, 2004: 139).

De ahí que la crítica decolonial acuñe el concepto de «modernidad-colonialidad» para explicar la implicación constitutiva del desarrollo del capitalismo y la expansión colonial, el ego cartesiano y el ego conquiro, el pensamiento ilustrado y el etnocentrismo. Para los teóricos decoloniales, la modernidad se inaugura en el siglo XV con la colonización de América y no en el XVIII con la Revolución francesa y la Revolución industrial. Junto a la anexión de las Indias Occidentales y la apertura del circuito de intercambios trasatlántico, se inicia el proceso de acumulación capitalista, la secularización de la vida social, la centralidad de la cultura europea y la instauración de la denominada «historia universal». Como lo han planteado Walter Mignolo, es por esta razón que la crítica decolonial puede considerarse como un conjunto de proyectos destinados a cuestionar el narcisismo histórico de la cultura europea y la razón moderna.

Estos proyectos forman un paradigma otro porque tienen en común la perspectiva y la crítica a la modernidad desde la colonialidad, esto es, ya no la modernidad reflejada a sí misma en el espejo, preocupada por los errores del colonialismo, sino vista por la colonialidad que la mira reflejarse a sí misma en el espejo. Y porque cuestiona la propia lógica mediante la cual la modernidad se pensó y se sigue pensando como modernidad (Mignolo, Historias locales, 27).

De ahí que la opción teórica decolonial plantee a la vez una doble operación: por un lado, de "desprendimiento» de las epistemologías occidentales que colonizaron los saberes y las disciplinas modernas; por otro, de «apertura» de un pensamiento otro que reinaugure una nueva forma de pensar desde la pluralidad de puntos de enunciación geohistóricamente situados: «El giro decolonial es la apertura y libertad del pensamiento y de formas de vida-otras (economías-otras, teorías políticas-otras); la limpieza de la colonialidad del ser y del saber; el desprendimiento de la retórica de la modernidad y de su imaginario imperial» (Mignolo, La idea de América Latina, 29).

Yo añadiría la necesidad de desprendernos de las teorías del arte y del cine construidas bajo parámetros de la razón eurocéntrica con la finalidad de permitir la apertura de

4 A pesar de que nociones «centro» $\mathrm{y}$ «periferia», «norte»y «sur» «occidente»y «no-occidente» han sido severamente cuestionadas por efectos de los medios, las migraciones, las hibridaciones culturales, cabe mencionar el esfuerzo que han hecho los teóricos decoloniales por alejarse de los binarismos del pensamiento moderno. Conceptos como «heterogeneidad histórico estructural» creado por Aníbal Quijano o «Transmodernidad» formulado por Enrique Dussel dan cuanta de esta búsqueda. Quizá donde aún existe un problema por saldar es en el uso del concepto de «matriz»o "patrón» aplicado para entender órdenes de dominación cultural abierta por la colonialidad. Estos conceptos pueden llevarnos a la errada idea de un «relato maestro» que impida comprender la colonialidad como una cadena de mediaciones y traducciones contingentes. 
una «estética-otra», de «culturas visuales-otras», de «tecnologías de la imagen-otras». $\mathrm{Al}$ igual que sucede en las Ciencias Sociales, en disciplinas y ramas vinculadas al arte y la imagen existe una amplia genealogía construida sobre la base de los desarrollos del mundo greco-latino, la tradición judeo-cristiana, el pensamiento ilustrado y la crítica posmoderna. Esta tradición, trasmitida a partir de la historia universal del arte, la estética y las teorías disciplinarias del arte, permanece hasta la actualidad incuestionada y sigue siendo el centro de organización de los programas de las carreras de Bellas Artes y Artes Visuales. Quienes trabajamos en la docencia dentro de las mencionadas carreras, nos encontramos siempre ante el dilema del lugar de ubicación de la historia del arte latinoamericano o la historia del cine latinoamericano ${ }^{5}$. La institución universitaria, para evitar un problema, suele agregar una materia apéndice que se construye a imagen y semejanza de la historia universal de las artes o el cine, pero que no es parte de ella. El desprendimiento epistemológico y la apertura decolonial que plantea Mignolo habla justamente del hecho de cuestionar las categorías eurocéntricas con las que nos formamos como profesionales dentro de las disciplinas de la imagen, con la finalidad de poder articular un pensamiento que habilite un lugar de enunciación para aquellos sujetos e historias que han sido silenciados por el eurocentrismo. Este pensamiento, por un lado, ya no puede corresponder con las disciplinas del arte y la imagen, sino que, a partir de un enfoque inter y transdisciplinar, abordaría la propia constitución de estos campos del saber articulados al surgimiento de la modernidad-colonialidad. Por otro, está abierto al diálogo interepistémico con saberes, imágenes y visualidades otras producidas por movimientos, grupos y culturas subalternos que desacatan la autoridad cultural del mundo occidental y que se expresan por fuera de las instituciones de conocimiento establecidas, como es el caso de las universidades.

Los debates sobre Cultura Visual que se dieron en el primer mundo partieron de un abandono del enfoque histórico en un paradigma antropológico integrador que analice la imagen, las tecnologías, las instituciones y las prácticas cotidianas del ver en tanto nuevas realidades del capitalismo globalizado (Mitchell, 25). Los debates sobre Cultura Visual pensados desde América Latina están llamados a reintroducir la historia en el pensamiento de la imagen y a plantear la discontinuidad geográfica que asedia al campo de la visualidad. Los estudios visuales reconceptualizados desde nuestra región exigen pensar la diversidad de historias y la heterogeneidad estructural que configuran la visualidad a nivel del sistema mundo-moderno. El no reconocimiento de esta «heterogeneidad histórico-estructural» es, según Aníbal Quijano, justamente lo que fundamenta la perspectiva eurocéntrica del conocimiento (222). Al negarse «la dependencia históricoestructural» de las historias visuales periféricas que se produjo por efectos de la colonialidad del poder, las expresiones simbólicas de América Latina - que incluyen su arte y su cine- simplemente dejan de tener lugar, caen en lo que Franz Fanon denominó como «la zona del no ser» ${ }^{6}$. Esto no quiere decir, que no existan historias del arte o del cine en América Latina, sino que tienen un paradójico estatus de existencia a través de cual su inscripción histórica y discursiva tiene que remitirse a un lugar epistémico de enunciación expropiado. Como lo ha advertido Quijano, la colonialidad del poder se constituyó

\footnotetext{
5 Queremos dejar sentado que existen relaciones diferenciadas entre la tecnología del cine (base fotográfica) y las tecnologías videográficas (base electromagnética y digital) con la colonialidad del saber y la producción institucional de conocimientos. Sin embargo, estos complejos matices no son objeto de este ensayo.

6 Respecto del concepto de «zona de no ser» consultar Gordon (2009), en Fanon (2009).
} 
como un patrón de dominación a partir del cual se establecieron jerarquías económicas, sociales, intersubjetivas y políticas entre identidades europeas y no europeas. A partir de la implantación de esta matriz de poder «Las culturas dominadas serían impedidas de objetivar de modo autónomo su propias imágenes, símbolos y experiencias subjetivas; es decir, con sus propios patrones de expresión visual y plástica. Sin esa libertad de objetivación, ninguna experiencia cultural puede desarrollarse» (99).

De ahí la dificultad que tengamos para hablar y pensar en términos teóricos sobre nuestras prácticas visuales y artísticas sin ser acosados por el fantasma de la particularidad que existe al margen de la universalidad y de la historia. Es por esta razón que una de las primeras tareas de los estudios visuales latinoamericanos es generar condiciones intelectuales para que su enunciación tenga lugar, para abrir la enunciación de la visualidad otra, para la visualización de una enunciación otra.

Dentro de los estudios latinoamericanos, la preocupación por el sujeto subalterno se centralizó en el análisis de la voz y el testimonio de los grupos dominados. Las imágenes y visualidades del subalterno ha sido una problemática poco estudiada. Sin embargo, la complejidad del proceso de colonización no sólo planteó una reorganización radical de las lenguas y los saberes, sino también una diversa rearticulación de las visualidades y las representaciones. Como lo ha planteado el historiador francés Serge Gruzinski ${ }^{7}$ ante los obstáculos de traducción con los que se encontró la lengua española frente a la pluralidad de lenguas indígenas y el persistente analfabetismo en la historia de América Latina, la imagen constituyó uno de los mecanismos fundamentales de occidentalización. A través del uso de representaciones visuales se produjo un proceso de colonización del imaginario indígena, permitiendo a la vez la proliferación de una cultura visual rica en hibridaciones y mestizajes que permitió que América Latina se convierta en un verdadero laboratorio intercultural de imágenes:

Si la América colonial era un crisol de modernidad es porque fue, igualmente, un fastuoso laboratorio de imágenes. En él descubrimos cómo las «Indias occidentales» entran en la mira de Occidente antes de afrontar, por oleadas sucesivas e interrumpidas, las imágenes, los sistemas de imágenes y los imaginarios de los conquistadores: de la imagen medieval a la imagen renacentista, del manierismo al barroco, de la imagen didáctica a la imagen milagrosa, del clasicismo al muralismo y hasta las imágenes electrónicas de hoy». (Gruzinski, 2003: 13).

Es quizá la colonialidad de las imágenes, el poder que ellas desplegaron y la resistencia que permitieron, el precedente más importante para la construcción de una cultura visual global en América Latina. Las industrias del espectáculo, los medios masivos de comunicación y la generalización de lo que Mirzoeff denominó «el acontecimiento visual» (Mirzoeff, 34) en la vida cotidiana no serían sino el resultado de una compleja heterogeneidad histórica-estructural de la modernidad visual que surge a partir del siglo xv. Las tecnologías del cine, la televisión, el video, la Internet y los celulares, en definitiva lo que Roncagliolo ha denominado como «la videosfera latinoamericana» (63-64), no serían sino un segundo momento de la modernidad visual de América Latina. En la actualidad parece haber un consenso en admitir que la dinámica de la reproducción cultural tiende a procesos imaginarios vinculados con el consumo y la apropiación de las imágenes

Para un análisis del papel jugado por las imágenes a lo largo de la historia de Latinoamérica ver Gruzinski (2000 y 2003). 
(Castro-Gómez y Guardiola-Rivera, XxiII). Este contexto abre nuevos campos de indagación para la crítica decolonial al exigir la consideración del papel de las imágenes en la producción y reproducción de «la diferencia colonial» y plantear el análisis geopolítico de la función que cumplen dispositivos, instituciones y saberes del arte y el audiovisual en la reproducción de la colonialidad del poder. Estamos asistiendo a un segundo momento del pensamiento decolonial en el cual la crítica de la visualidad adquiere relieve. Como lo ha planteado el propio Mignolo: «Es en este momento, cuando empezamos a descubrir que la colonialidad se engancha con lo visual. Por eso decimos que estamos en la matriz colonial de poder, segunda época» (Cartagena, et al., Matriz colonial del poder).

\section{VISUALIDAD Y DIFERENCIA COLONIAL}

A pesar de estas dificultades, en la actualidad han empezado a desarrollarse distintos estudios que cuestionan las disciplinas artísticas y el régimen de la mirada desde conceptos propuestos por la crítica decolonial ${ }^{8}$. Estos estudios están abriendo nuevas rutas para pensar la relación entre visualidad, poder y conocimiento en el contexto de la matriz colonial de dominación inaugurada con la primera modernidad. Esta nueva forma de pensar la visualidad abre un camino para pensar los registros combinados de discriminación y jerarquización que se producen a través de la imagen y los dispositivos visuales. Como lo planteó en su momento Keith Moxey, uno de los desafíos pendientes para los estudios de visualidad es la crítica del universalismo que subyace oculto tras la denominación «cultura visual» y que impide pensar las jerarquías de clase, género, raza y nación (Moxey, 114). Pensar en una estrategia conceptual para el análisis combinado de los múltiples patrones de discriminación es realmente un desafío para los estudios transdisciplinarios, no sólo en el campo visual, sino también en el cultural y social. La crítica decolonial ha avanzado importantes consideraciones al respecto que pueden constituirse en una bisagra epistemológica para pensar las relaciones entre poder y visualidad. Sobre la base del concepto de «diferencia colonial», la crítica decolonial ha ido articulando una compleja indagación sobre las distintas esferas de dominación que surgen con la modernidad-colonialidad. Para los pensadores latinoamericanos, la constitución del sistema-mundo moderno-colonial estructura un poderoso universo de categorías que transforman la diferencia en jerarquía. A través de la razón moderna eurocentrada que organiza el mundo en oposiciones binarias se organiza un orden cuya lógica es la dominación: «La diferencia colonial consiste en clasificar grupos de gentes o poblaciones e identificarlas en sus faltas o excesos, lo cual marca la diferencia y la inferioridad respecto a quien clasifica» (Mignolo, Historias locales, 39).

Autores como Quijano, Mignolo y Castro-Gómez, consideran que el eje vertebrador de la colonialidad del poder se funda sobre el concepto de raza, en tanto éste se convirtió en «un modo de otorgar legitimidad a las relaciones de dominación impuestas por la colonia» y en «el primer criterio fundamental para la distribución de la población mundial»

\footnotetext{
Para un cuestionamiento de los campos artísticos desde conceptos vinculados al pensamiento decolonial ver: Marín Hernández (2005), Cartagena (2006 y 2010), León (2006 y 2010), Barriendos (2007 y 2008), Palermo (2009), Mignolo (2010), Franco Reyes (2010). Adicionalmente existen trabajos similares en el campo musical y sonoro: Santamaría Delgado (2007) y Estévez Trujillo (2008 y 2010).
} 
(Quijano, 203). Sobre esta base, se comienza a pensar de manera analógica toda otra serie de relaciones de dominación que surgen en los campos de la sexualidad, la autoridad, la subjetividad y el trabajo con la instauración de la modernidad-colonialidad, que luego se convierten en sistemas de poder desterritorializados de la gubernamentalidad colonial global. La tesis central es que en América durante los siglos XV y XVI se experimentan y producen una serie de dispositivos de dominación articulados en red que alcanzarán su perfeccionamiento en la época clásica de ilustración durante el siglo XVII. Ramón Grosfoguel describe así la operación múltiple y compleja de la colonialidad: «Un hombre / europeo / capitalista / militar / patriarcal / blanco / heterosexual / masculino llega a las Américas y establece simultáneamente en el tiempo y en el espacio varias jerarquías / dispositivos de poder globales enredados entre sí» (Grosfoguel, 103).

El sociólogo puertorriqueño identifica al menos nueve jerarquías surgidas como efecto de la instauración del sistema-mundo moderno-colonial en los siguientes campos: 1) Clase; 2) División internacional del trabajo; 3) Sistema interestatal global; 4) Dimensión etno/ racial global; 5) Género; 6) Sexualidad; 7) Espiritualidad; 8) Epistemología; 9) Lengua.

Frente a esta enmarañada red de jerarquías interdependientes cabría quizá añadir una décima, vinculada a los códigos visuales y a las maneras de objetivizar la mirada tal y como lo plantea Quijano en un pasaje citado con anterioridad.

Efectivamente, existe una jerarquía marcada entre sistemas visuales occidentales y no-occidentales desplegada a partir de una serie de mecanismos tecnológicos, iconográficos, psicológicos y culturales integrados a sistemas coloniales de poder y conocimiento. La misma noción de imagen requiere ser decolonizada ya que ésta es producto de la retícula óptica, la perspectiva renacentista, el concepto occidental de representación y el sujeto trascendental moderno. Como lo ha planteado Gruzinski, «las categorías y clasificaciones que aplicamos a las imágenes son inherentes a una concepción culta debido al aristotelismo y al renacimiento» (La guerra de las imágenes, 14). La noción de «ixilptla» que los indígenas nahuas usaron para referirse a sus íconos milagrosos fue combatida como idolatría y posteriormente subsumida por efectos de la colonialidad del poder por el concepto occidental de «imagen» asociado al catolicismo. Al igual que las lenguas, los códigos de la mirada y la visualidad se interseccionan con los demás órdenes jerárquicos de la modernidad-colonialidad y sirven como parámetros para la racialización e inferiorización de las poblaciones no europeas. Por lo tanto, podríamos afirmar que uno de los efectos de la colonización del poder y el conocimiento fue la asimilación de la multiplicidad de culturas visuales al orden binario del eurocentrismo que asigna lugares hegemónicos y subalternos para cada una de ellas.

Más aún, podría argumentarse que las culturas visuales racializadas e inferiorizadas a través de las múltiples y combinadas discriminaciones y jerarquizaciones de la modernidad-colonialidad terminan perdiendo su capacidad de significar convirtiéndose en un puro objeto significado. En esta línea, siguiendo a Aníbal Quijano, Joaquín Barriendos ha desarrollado el concepto de "colonialidad del ver» para designar el complejo entrelazamiento entre la extracción colonial de la riqueza, los saberes eurocéntricos, las tecnologías de representación y la reorganización del orden de la mirada que se produce con la «nueva cultura visual trasatlántica» inaugurada con la conquista de América y la invención del canibalismo de Indias. Para el historiador mexicano, «la colonialidad del ver» se produce por la confluencia del expansionismo trasatlántico de las culturas visuales imperiales, el ocularcentrismo militar-cartográfico, el saber proto-etnográfico 
eurocentrado y la génesis del sistema mercantil moderno-colonial. Cuando estos factores se conjugan, se produce una compleja epistemología visual que estructura, por un lado, un orden de descorporización e invisibilización que permite la universalización de la mirada imperial y, por otro, un orden de corporización y visibilidad que permite la racialización del cuerpo indígena a través del tropo del canibalismo. La colonialidad del ver se presenta así como una articulación geopolítica de la mirada y lo mirado en un juego de doble antropofagia:

La «doble desaparición» antropófaga se completa entonces con la «invisibilidad» evidente del observador (del que escrutiña y rumia con su mirada lo ignoto y lo salvaje), por un lado, y con la invisibilización táctil y consumible (deshumanización etnográfica radical) de lo caníbal, de esa presencia ominosa y abyecta del «mal salvaje» que sólo debe hacerse visible como una forma de negación de su existencia, por el otro. Ante este doble régimen de lo desapercibido se puede decir entonces que tanto el «descubrimiento» del Nuevo Mundo como la invención de su monstruosidad inherente se corresponden simétricamente con el nacimiento de una nueva economía visual trasatlántica por un lado y con una cultura visual etnocéntrica propiamente capitalista y propiamente antropófaga por el otro (Barriendos, 2008).

Frente al mito universalista y transparente de la modernidad, la colonialidad del ver nos permite reconocer el posicionamiento de la mirada y lo mirado en una doble situación que Grosfoguel reconoce a partir del cruce de «la geopolítica del conocimiento» y «la corpo-política del conocimiento» (Grosfoguel, Implicaciones de las alteridades, 100). Es así como se establece la profunda imbricación que tiene la visualidad con las jerarquías no sólo geográficas, espirituales, étnicas, lingüísticas, sino también raciales, de clase, de género y sexuales. A partir del estudio de la relación de los dispositivos visuales con la colonialidad del poder, permanentemente negada por el eurocentrismo y el occidentalismo, es posible entender las diversas jerarquías producidas en la época de la reproductibilidad técnica de la imagen.

\section{DISPOSITIVOS AUDIOVISUALES Y TELECOLONIALIDAD}

Frente a la colonialidad del ver estudiada por Barriendos en la primera modernidad en base al canibalismo de Indias, es necesario plantear la reconceptualización de las tecnologías coloniales de poder en la época de la reproductibilidad técnica de la imagen. La tesis central que sostengo es que en la actualidad los dispositivos audiovisuales se han convertido en una red de mediaciones que actualizan la colonialidad del ver en un momento caracterizado por el capitalismo cognitivo, la era de las comunicaciones, las tecnologías de la imagen, la cultura visual, las industrias culturales y la incorporación occidental del otro en el contexto de la globalización. Esta nueva circunstancia va a configurar una telecolonialidad visual caracterizada por una forma de colonización del imaginario y la memoria vinculada a la particular operación de la imagen producida y reproducida mecánicamente.

La historia de esta redefinición de la colonialidad del ver puede rastrearse a partir del aparecimiento de dos tecnologías innovadoras que transformaron el acto mismo de la observación: la fotografía en 1826 y el cine en 1895. Gracias a la generalización de 
estas tecnologías se inicia en los países centrales del sistema-mundo una reflexión sobre el lugar de la imagen dentro del capitalismo y del sistema general de la cultura. Según Walter Benjamin, la imagen es incorporada al consumo masivo adquiriendo un nuevo estatus que privilegia la reproducción técnica sobre la singularidad aurática y la cercanía espacio-perceptiva sobre la lejanía metafísica (Benjamin, 24). Como lo planteo en otro lugar, el aparecimiento de las tecnologías mecánicas de captura de la imagen plantea una compleja reorganización del poder y la gubernamentalidad fundada en el paso de los dispositivos panópticos de los siglos XVII y XVIII a los dispositivos audiovisuales de los siglos XIX y Xx. A partir de esta transformación, la economía del poder vinculada a los dispositivos audiovisuales empieza a definirse a partir de cinco principios: a) Descentramiento de la mirada; b) Traducción del cuerpo al régimen bidimensional de la representación; c) Generalización del efecto de omnipresencia de sujeto trascendental; d) Dislocación del tiempo y el espacio que permite una acción diferida y a distancia, e) Introducción del placer escópico (León, Reinventando al otro).

Estas innovaciones tecnológicas tienen una especial significación cuando se las piensa desde la heterogeneidad estructural de las regiones periféricas del sistema mundomoderno y en relación a la analítica de la colonialidad del poder. Con la invención de estas nuevas máquinas de observar se produce una base técnica para nuevos procesos de sujeción fundados en los viejos principios del poder colonial. Por un lado, se hace posible el desarrollo y la desmaterialización de la mirada imperial moderno-colonial que adquiere la capacidad de dislocarse en múltiples puntos de observación identificados con el ego conquiro. Por otro lado, la captura del tiempo que posibilitan las tecnologías visuales a partir de la invención del cine permite un complejo proceso de sincronización de las temporalidades pluriversales de los distintos pueblos del planeta a partir de la homogeneidad del tiempo moderno. La génesis de este proceso arranca con la instauración cinematográfica del tiempo de la nación occidental y termina con la trasmisión planetaria de espectáculos deportivos, culturales y sociales en vivo y en directo a nivel mundial agenciada por las empresas transnacionales de la comunicación? 9 .

Paralelamente, la imagen audiovisual se convierte en mecanismo de control, conocimiento y visualización de la alteridad geo y corpopolíticamente situada en los márgenes de Occidente. Basta recordar que la articulación en red de los dispositivos audiovisuales producida a lo largo del siglo xx coincide con una amplia reestructuración de la colonialidad del poder, el conocimiento y el ser. Dentro del pensamiento decolonial, esta recomposición de la colonialidad ha tenido varias formulaciones que pueden describirse en el paso del eurocentrismo al globocentrismo (Coronil, 2000), de la colonialidad del poder a la poscolonialidad del poder (Castro-Gómez, 2007), del colonialismo global a la colonialidad global (Grosfoguel, 2007). Estas formulaciones tienden a cuestionar la idea de que la posmodernidad y la globalización hayan generado una crisis de la modernidad y sus formas de opresión coloniales. Por el contrario, plantean que el capitalismo cognitivo, que tiene al conocimiento y la comunicación como principal fuerza productiva, es una

\footnotetext{
Respecto al origen de esta sincronización geopolítica del tiempo, por efecto del dispositivo cinematográfico, escribí en otro lugar: «En sociedades plurinacionales, la gran tarea del Estado fue transformar los tiempos heterogéneos que viven las distintas comunidades y pueblos en el tiempo homogéneo de la Nación. El cinematógrafo con su capacidad para homogeneizar el tiempo y volverlo lineal estableció un modelo para la construcción de la Nación. Antes del predominio de la televisión, el cine mostró el camino para la sincronización de tiempos y la anulación de tiempos «otros» en el que vivían las naciones y comunidades subalternas». (León, Biopolitica, 35).
} 
manera de continuación de la colonialidad por otros medios que afianzan la explotación colonial del conocimiento de las regiones no-occidentales (Castro-Gómez, 84). Cada vez más, el poder se encuentra desvinculado de los antiguas instituciones coloniales, se disemina en el mercado mundial, las grandes empresas transnacionales y la cultura global euro-norteamericanas. Esto hace que el poder adopte formas menos visibles pero más concentradas basadas en el mercado en donde los conflictos culturales están atenuados por medio de la incorporación del otro. Las maneras de establecer las diferencias culturales se trasladan del concepto de «alteridad» al de «subalternidad» (Coronil, 246). Efectivamente, en este nuevo escenario económico-cultural, las regiones periféricas del sistema-mundo moderno siguen sometidas a las múltiples jerarquías de la colonialidad ocupando una posición subordinada en la división internacional del trabajo y siendo sometidas a procesos de inferiorización y racialización a nivel global (Grosfoguel, Implicaciones de las alteridades, 106).

A partir de estas reflexiones, es posible pensar el papel que cumplen los medios audiovisuales en la producción y reproducción de lo que podríamos llamar como «tele-colonialidad», que trabaja sobre el control geopolítico de la alteridad a nivel global basado en la administración de imágenes a distancia. La tele-colonialidad visual nos pone de frente a una red de dispositivos mediáticos transnacionales que se basan en la explotación colonial de conocimientos, representaciones e imaginarios y que tienen como finalidad la reproducción de las jerarquías de clase, raciales, sexuales, de género, lingüísticas, espirituales y geográficas de la modernidad-colonialidad euro-norteamericana. Los dispositivos mediáticos articulados dentro del régimen de la tele-colonialidad van a plantear una rearticulación de la diferencia colonial en dos campos: a) Nuevos parámetros para la división internacional del trabajo tecnológico, y b) Un nuevo estatuto para la racialización de la población a nivel mundial.

\section{DIVISIÓN INTERNACIONAL DEL TRABAJO TECNOLÓGICO}

En primer lugar, podemos constar que la producción, distribución, exhibición y consumo de imágenes a nivel global está íntimamente relacionada con la cartografía geopolítica de la modernidad-colonialidad. La sociedad del espectáculo y la comunicación se construye sobre la base de la economía-mundo moderna y sus formas de articulación entre centros y periferias. La división internacional del trabajo asociada a estas estructuras se rearticula en el siglo xx de acuerdo a las necesidades del capitalismo cognitivo. Las industrias culturales vinculadas a la reproducción técnica de la imagen expresan de forma clara la nueva repartición de funciones dentro de la economía global del espectáculo. Armand Mattelart explica estos cambios en los siguientes términos:

Durante el periodo de entreguerras Europa se inquieta por la pérdida de las herramientas de su predominio intelectual. El universalismo de la cultura de masas se adelanta al proyecto cosmopolita de la cultura clásica, legado por la Ilustración. En el desplazamiento entre una y otra las relaciones culturales se transforman en herramienta geopolítica. [...] El cine se convierte en el emblema de las relaciones de fuerza que va a dejar huella en la internacionalización de la producción cultural (37). 
En este parágrafo, el sociólogo belga lanza una tesis tan ajustada en una de sus partes, como problemática en otra. Por un lado, plantea una justa ponderación del cine, en tanto empresa cultural que permitió superar la crisis del primer eurocentrismo desencadenado por el agotamiento de la cultura ilustrada. Sin embargo, su acierto está acompañado de un desliz etnocentrista que mantiene una posición poco crítica respecto al cosmopolitanismo y la universalidad atribuidos a la singularidad europea. Mucho más agudos en su análisis geopolítico de las tecnologías son Shohat y Stam, quienes ponen en la balanza los desarrollos de las industrias audiovisuales periféricas, los flujos migratorios y comunicativos globales:

A pesar de la imbricación del «Primero» y del «Tercer» mundos, la distribución global del poder todavía tiende a considerar a los países del Primer Mundo «trasmisores» y a reducir a la mayoría de países del Tercer Mundo al papel de «receptores» (una consecuencia de esta situación es que las minorías del Primer Mundo tienen el poder de proyectar sus proyecciones culturales por todo el mundo). En este sentido, el cine hereda las estructuras establecidas por la infraestructura de comunicaciones del imperio, las redes del telégrafo y de teléfono y los aparatos de información que ligan los territorios coloniales a la metrópoli, permitiendo a los países imperialistas controlar las comunicaciones globales y modelar la imagen de lo que pasa en el mundo (Shohat y Stam, 50).

De esta manera nos acercamos a considerar la distribución internacional del trabajo generada por las sociedades imperiales del espectáculo. Siguiendo la lógica de la colonialidad del poder y del conocimiento, la invención tecnológica, la innovación cultural, la creación de modelos narrativos y la producción industrial quedan del lado de las sociedades euroamericanas del primer mundo; mientras, la aplicación tecnológica, las franquicias culturales, la adaptación de modelos y el consumo mediático quedan del lado de las poblaciones periféricas del planeta. Estas nuevas formas de organización de la economía del espectáculo no hacen sino afianzar la colonialidad y el imperialismo cultural lejos de las celebraciones del consumo activo que tanto es celebrado en la actualidad.

\section{RACIALIZACIÓN GLOBAL DE LA POBLACIÓN}

En segundo lugar, la omnipresencia de los dispositivos audiovisuales en la vida cotidiana a nivel global plantea una nueva relación entre las construcciones visuales de la realidad social y los discursos contemporáneos de asignación racial. A partir de la invención de la fotografía y el cine, el estatuto de la asignación racial empieza a cambiar, trasladándose desde las construcciones del discurso ilustrado de la ciencia a las representaciones masivas instaladas en el consumo cotidiano. De ahí que Stuart Hall sostenga que, durante el siglo xx, las prácticas significativas tendientes a señalar la diferencia racial y la otredad cultural constituyeron un «régimen racializado de representación» (Hall, 249). Los procesos de racialización cada vez más se fueron articulando al estatuto de la cultura visual y su lógica de visibilización construida a partir de regímenes escópicos y de los dispositivos audiovisuales. La raza, en tanto construcción geopolítica de la colonialidad del poder, empieza a ser asociada a la diferencia visible encarnada en la piel. De ahí que Frantz Fanon asocie la violencia y discriminación racial a la mirada del hombre blanco europeo que reduce la diferencia cultural al «esquema epidérmico corporal»(Fanon, 
113). Al mismo tiempo que el realismo fotográfico, asociado a los dispositivos de captura de la imagen, se convierte en un principio epistemológico de producción de verdad, la racialización de la diferencia se transforma en una realidad natural incontrovertible que tiene su demostración en el registro visual. La diferencia cultural empieza a ser capturada, conocida y administrada a través de los vectores de luz de los regímenes escópicos que tramitan la significación, el deseo y el control de la otredad.

Quien ha trabajado adecuadamente esta visión constitutiva entre raza y visión es Deborah Pool (2000). A partir del análisis de la economía visual en los Andes peruanos y bolivianos, la antropóloga estadounidense analiza cómo: a) la materialidad de las imágenes plasmaron las concepciones de raza como un hecho biológico, b) la fantasía y el deseo jugaron un rol importante en esta operación, y c) las imágenes racializadas de los sujetos no occidentales tuvieron un rol importante en la constitución de la modernidad europea. Pool señala de esta manera los objetivos de su investigación:

Al reflexionar en torno a cómo la raza está representada en la economía visual, estoy interesada en comprender, por un lado, la relación que ocurrió entre los regímenes perceptivos europeos modernos y el creciente interés de los europeos en los pueblos no-europeos y, por otro, en entender el proceso por el cual las imágenes visuales han dado forma a las percepciones europeas en torno a la raza como un hecho biológico y material (Pool, 27).

Para la antropóloga norteamericana, las tecnologías que facilitaron la producción y reproducción de imágenes en serie van a tener una especial significación en sociedades caracterizadas por su pluralidad étnico-cultural y la persistencia de patrones de segregación raciales. Al igual que las tecnologías estadísticas y la administración estatal, las tecnologías de la imagen van a contribuir a definir y jerarquizar a la población a partir de los principios de tipificación, comparabilidad y equivalencia destinadas a clasificar vigilar, y controlar a la población (Pool, 24). De ahí que una de las tareas pendientes para los estudios visuales latinoamericanos sea pensar esta relación constitutiva entre racialización y visualidad sobre el telón de fondo de la colonialidad. Como lo ha planteado Joaquín Barriendos: Cualquier disciplina, indisciplina o interdisciplina visual que se enfoque en América Latina debería tener como prioridad, digamos, en el problema de la racialización (León y Schelenker, 2010).

Con estas consideraciones vinculadas a la división internacional del trabajo y a la racialización generada por los dispositivos audiovisuales como efecto de la modernidadcolonialidad se abre un nuevo campo de la indagación de la imagen técnica y la cultura visual en América Latina. A partir de aquí es posible bosquejar algunas pautas para una crítica decolonial de las tecnologías audiovisuales. Frente al determinismo tecnológico, que plantea que los medios audiovisuales son un fenómeno de los siglos xx y xxi, la crítica decolonial permite situar los dispositivos y aparatos de grabación y reproducción de imagen en la genealogía de larga duración de la modernidad-colonialidad que se remonta al siglo xv. Frente al determinismo cultural, que plantea la pretensión de que estas tecnologías son un desarrollo exclusivo de la racionalidad europea, nos permite pensar los múltiples condicionamientos entre centro y periferia que han permitido un desarrollo corresponsable del discurso audiovisual en el contexto de la mundialización de la cultura. Finalmente, frente a la crítica eurocentrada del dispositivo, permite establecer las distintas jerarquías raciales, de clase, de género, geográficas y espirituales que se establecen a través de la cultura visual moderno-colonial global. 


\section{CONCLUSIONES}

Finalmente, a manera de conclusión quisiera puntualizar algunas de las tesis que he venido sosteniendo en este texto con la finalidad de iniciar una discusión acerca del proyecto de los estudios visuales en América Latina, las tecnologías audiovisuales y la crítica decolonial:

1. La visualidad no obedece a procesos homogéneos y continuos sino que está atravesada por una estructura de elementos heterogéneos que articulan historias diversas a nivel geopolítico por la colonialidad del poder.

2. Por efectos de la heterogeneidad histórico-estructural, el concepto de cultura visual se revela como un fenómeno discontinuo articulado dentro de los regímenes de larga duración del sistema-mundo moderno-colonial. Son reconocibles entonces múltiples culturas visuales que ocupan lugares hegemónicos y subalternos por efectos de la colonialidad.

3. Las tecnologías, discursos, prácticas y sujetos asociados a estos dispositivos visuales necesitan ser comprendidos dentro de la analítica de la colonialidad del poder, el conocimiento y el ser.

4. Los dispositivos audiovisuales operan a partir de una red de mediaciones que actualizan la colonialidad del ver en un momento caracterizado por el capitalismo cognitivo, la era de las comunicaciones, las tecnologías de la imagen, la cultura visual, las industrias culturales y la incorporación occidental del otro en el contexto de la globalización.

5. A partir de la relación entre dispositivos audiovisuales y colonialidad, reprimida por el eurocentrismo y el occidentalismo, es posible entender las jerarquías raciales, de clase, sexuales, de género, lingüísticas, geográficas y espirituales producidas en la época de la reproductibilidad técnica.

6. El giro decolonial en los estudios visuales puede convertirse en una poderosa estrategia para realizar las tareas pendientes que dejaron los movimientos antiimperialistas y anticolonialistas en el campo del cine y el arte latinoamericano con la finalidad de construir una cultura visual transmoderna.

\section{REFERENCIAS}

Barriendos, Joaquín. «Apetitos extremos. La colonialidad del ver y las imágenes-archivo sobre el canibalismo de Indias». Trasversal. Eipcp. 2008. Sitio Web.

. Geoestética y trasculturalidad. Políticas de la representación, globalización de la diversidad cultural e internacionalización del arte contemporáneo. Fundació Espais D’Art Contempori: Girona, 2007. Medio impreso.

Benjamin, Walter. Discursos interrumpidos I, Madrid: Taurus, 1973. Medio impreso.

Cartagena, María Fernanda, et al. «Matriz colonial del poder, segunda época», Quito, entrevista a Walter Mignolo». Quito, 13 de agosto 2009. LatinArt. Sitio Web.

Castro-Gómez, Santiago. «El capítulo faltante de Imperio. La reorganización posmoderna de la colonialidad en el capitalismo posfordista». ¿Uno solo o varios mundos? Diferencia, subjetividad y conocimientos en las ciencias sociales contemporáneas. 
Mónica Zuleta et al. (eds.). Bogotá: Siglo del Hombre Editores y Santiago: Universidad Central, 2007. Medio impreso.

Castro-Gómez y Ramón Grosfoguel (eds.). El giro decolonial Reflexiones para una diversidad epistémica más allá del capitalismo global. Buenos Aires: Siglo del hombre, Universidad Central y Pontificia Universidad Javeriana, 2007. Medio impreso.

Castro-Gómez y Oscar Guardiola-Rivera. "Geopolíticas del conocimiento o el desarrollo de impensar las ciencias sociales en América Latina». La reestructuración de las ciencias sociales en América Latina. Bogotá: CEJA, 2000. Medio impreso.

Coronil, Fernando. "Naturaleza del poscolonialismo: del eurocentrismo al globocentrismo». La colonialidad del saber: eurocentrismo y ciencias sociales. Perspectivas Latinoamericanas. Edgardo Lander (comp.). Buenos Aires: CLACSO, 2000. Medio impreso.

Deleuze, Gilles. Michael Foucault, filósofo. Barcelona: Gedisa, 1995. Medio impreso.

Dussel, Enrique. «Transmodernidad e interculturalidad: interpretación desde la filosofía de la liberación». Crítica intercultural de la filosofía latinoamericana actual. Raúl Fornet-Betancourt (ed.). Madrid: Trotta, 2004. Medio impreso.

. «Europa, modernidad y Eurocentrismo». Colonialidad del saber: eurocentrismo y ciencias sociales. Perspectivas latinoamericanas. Edgardo Lander (comp.). Buenos Aires: CLACSO, 2000. Medio impreso.

Fanon, Frantz. Piel negra, máscaras blancas. Madrid: Akal, 2009. Medio impreso.

Foucault, Michael. Las palabras y las cosas. México: Siglo XXI, 1986. Medio impreso.

García Canclini, Néstor. «El poder de las imágenes. Diez preguntas sobre su redistribución internacional». Revista de Estudios Visuales 4. 2007. CENDEAC, Murcia. Medio impreso.

Grosfoguel, Ramón. «Hacia un pluriversalismo transmoderno decolonial». Tabula Rasa 9. 2008. Bogotá. Medio impreso.

- «Implicaciones de las alteridades epistemológicas en la redefinición del capitalismo global: transmodernidad, pensamiento fronterizo y colonialidad global». Uno solo o varios mundos. Diferencia, subjetividad y conocimientos en las ciencias sociales contemporáneas. Eds. Mónica Zuleta et al. Bogotá: Siglo del Hombre Editores y Santiago: Universidad Central, 2007. Medio impreso.

Gruzinski, Serge. La guerra de las imágenes. De Cristóbal Colón a «Blade Runner» (1492- 2019). México: FCE, 2003.

. El pensamiento mestizo. Barcelona: Paidós, 2000.

Hall, Stuart. «The Spectacle of the 〈Other». Representation. Cultural Representations and Signifying Practices. Gran Bretaña: SAGE, 1997.

León, Christian. Reinventando al otro. El documental indigenista en Ecuador. Quito: Consejo Nacional de Cinematografía, 2010.

. «Regímenes de poder y tecnologías de la imagen (Foucault y los Estudios Visuales)». 2010. Sitio Web.

. «Biopolítica, cine y otredad». Retrovisor 4 (2009). Quito.

"Apuntes para el análisis del documental indigenista en Ecuador» Kipus. Revista Andina de Letras. 20 (2006).

León, Christian y Alex Schelenker. «Diálogos sobre la colonialidad del ver. Entrevista con Joaquín Barriendos». 1 mayo 2010. Sitio web. 
Marín Hernández, Elizabeth. Multiculturalismo y crítica poscolonial: La diáspora artística latinoamericana (1990-2000). Memoria de la tesis de doctorado en Historia del Arte. Barcelona: Universidad de Barcelona, 2005.

Mattelart, Armand. Diversidad cultural y mundialización. Barcelona: Paidós, 2006.

Mignolo, Walter. La idea de América Latina. La herida colonial y la opción decolonial. Barcelona, Gedisa, 2007. . «Globalización doble traducción e interculturalidad». deSignis 6 (2004). Barcelona. Medio impreso.

. «Colonialidad del poder y subalternidad». Convergencia de tiempos. Ilena Rodríguez (ed.). Atlanta: Rodopi, 2001.

_-_. Historias locales / diseños Globales. Colonialidad, conocimientos subalternos y pensamiento fronterizo. Madrid: Akal, 2000. Medio impreso.

Mirzoeff, Nicholas. Una introducción a la cultura visual. Barcelona: Paidós, 2003. Medio impreso.

Mitchell, W. J. T. «Mostrando el ver: una crítica de la cultura visual». Revista de Estudios Visuales 1 (2003). Medio impreso.

Moxey, Keith. «Estética animada». Revista de Estudios Visuales 1 (2003). Medio impreso.

Pool, Deborah. Visión, raza y modernidad. Una economía visual del mundo andino de imágenes. Lima: Sur Casa de Estudios del Socialismo, 2000. Medio impreso.

Richard, Nelly. Fracturas de la memoria. Arte y pensamiento crítico, Siglo XXI: Buenos Aires, 2007. Medio impreso.

Shohat, Ella y Robert Stam. Multiculturalismo, cine y medios de comunicación. Barcelona: Paidós, 2002. Medio impreso.

Quijano, Aníbal. "Colonialidad del poder, eurocentrismo y América Latina». Edgardo Lander (comp.). La colonialidad del saber: eurocentrismo y ciencias sociales. Perspectivas latinoamericanas. Buenos Aires: CLACSO, 2000. Medio impreso.

_-_. "Colonialidad del poder, cultura y conocimiento en América Latina». Pensar (en) los intersticios. Teoría y práctica de la crítica poscolonial. Santiago Castro-Gómez, Oscar Guardiola-Rivera, y Carmen Millán de Benavides (eds.). Bogotá: Pontificia Universidad Javeriana, 1999.

Stam, Robert. Teorías de cine. Barcelona: Paidós, 2001.

Wallerstein, Inmanuel. Capitalismo histórico y movimientos antisistémicos. Un análisis de sistemas-mundo. Madrid: Akal, 2004. 